Planning for climate change across borders: insights from the Gold Coast (QLD) Tweed (NSW) region

Authors: Singh-Peterson L., Serrao-Neumann S., Crick F. and Sporne I. 


\title{
Planning for climate change across borders: insights from the Gold Coast (QLD) - Tweed (NSW) region
}

\begin{abstract}
Climate change impacts challenge artificially imposed administrative boundaries and expose the need for improved collaboration across borders. However, jurisdictional boundaries represent one of the major obstacles to an integrated response to climate change impacts. Overcoming this barrier is particularly challenging in cases requiring collaboration of institutions operating under different jurisdictions. This paper focuses on the challenges to cross-border institutional arrangements and implications for climate change adaptation in the planning sector. Drawing on empirical insights, the paper identifies the key challenges for cross-border arrangements at local and state levels broadly. It then uses the example provided by the Tweed River Entrance Sand Bypassing Project operative in the Gold Coast (QLD) and Tweed (NSW) border region to discuss the complexity of planning for climate change adaptation across borders.
\end{abstract}

Key words: planning, climate adaptation, coastal, cross-border, institutional arrangements

\section{Introduction}

Australia is a coastal nation with around $85 \%$ of its population residing in coastal areas (Department of Climate Change, 2009). The combination of ongoing population growth and forecasted climate change impacts is likely to place many coastal communities in Australia at risk (Hennessy et al., 2007). Additionally, Australian cities have inherited a legacy of past planning decisions that placed infrastructure and development in areas, such as low lying coastal zones, that are likely to be severely affected by climate change impacts (Department of Climate Change, 2009).

Urban planning plays a central role in reducing the impacts of and adapting to climate change as it controls and manages land use and development (Wilson, 2006; Blanco et al., 2009). However, to plan for effective climate change adaptation the planning sector will have to deal with multiple borders that currently impede integrated responses, including jurisdictional, institutional and sectoral borders. For example, as the planning system in Australia is defined by institutional arrangements set at the state level but mostly implemented at the local government level, cross-border responses involving local governments under distinct state jurisdictions require endorsement at the state level. Additionally, from an institutional and sectoral perspective, while planning and governance frameworks in Australia have advanced to facilitate better policy integration across scales, 
sectoral policy and decision-making continues to dominate the overarching framework for urban planning and development (Morrison, 2007; Norman, 2009). Consequently, in the absence of better vertical and horizontal coordination, planning and management responses are often overlapping, conflicting, juxtaposed and un-coordinated (Nicholson-Cole and O'Riordan, 2009). Furthermore, the success of innovative platforms of cross-border initiatives is dependent on the ability of institutions to secure financial resources and technical competencies (Perkmann, 2007). Hence, planning for climate change adaptation in cross-border regions under distinct state jurisdictions is challenging.

Infrastructure planning and delivery comprises a useful example to illustrate the institutional complexity related to climate change adaptation (Bulkeley et al., 2009). Urban infrastructures are identified to play a critical role in addressing climate change impacts in urban areas (Serrao-Neumann et al., 2011). For example, they provide critical access routes for emergency purposes, stormwater management and flood control as well as coastal defences. They are also often costly and demand a great deal of certainty in funds. Thus, in cross-border regions, infrastructure planning will need to be well orchestrated to enable communities to adapt to climate change impacts. However, this represents a significant challenge as infrastructure funding, provision and ownership of assets fall under the auspices of multiple stakeholders, such as local, state and federal governments as well as the private sector (Zimmerman and Faris, 2010).

This paper contributes to this Special Issue's theme of planning across borders by discussing the challenges to cross-border institutional arrangements and implications for climate change adaptation in the planning sector. The paper focuses on the Tweed River Entrance Sand Bypassing Project (TRESBP) - a cross-border infrastructure response to coastal erosion in the Gold Coast (QLD) and Tweed (NSW) border region. TRESBP provides great scope for the discussion of the challenges the planning sector is likely to face, as risks to coastal property and infrastructure from climate change continue to manifest particularly in urbanised coastal areas. To this end, the paper is structured in three parts. The first part highlights broad challenges for the planning sector associated with climate change adaptation. The second part identifies key planning challenges specifically related to cross-border institutional arrangements drawing on empirical data based on the Gold Coast/Tweed border region. In the third part we bring together these distinct, yet intricately dependent, two sets of challenges to discuss their implications for planning across jurisdictional boundaries under a changing climate. We do so by focusing on the TRESBP case. The paper concludes by highlighting insights that can inform the planning sector when planning for climate change adaptation across borders. 


\section{First Set of Challenges: Adapting to Climate Change}

Despite the growing recognition of the importance of planning for and adapting to the unavoidable impacts of climate change, there remains a gap between rhetoric and actual implementation of adaptation policies and actions. Adaptation is a complex process and it is increasingly recognised that there are many challenges to effective and successful adaptation (Repetto, 2008; Adger and Barnett, 2009; Berrang-Ford et al., 2011; Ford et al., 2011).

First, a key challenge for policymakers will be to ensure that adaptation policy delivers its intended objectives and doesn't result in maladaptation. Maladaptation occurs when an action intended to reduce vulnerability to climate change leads instead to an increase in vulnerability and/or to additional impacts (Reilly and Schimmelpfennig, 2000; Barnett and O'Neill, 2010). Specifically, maladaptation occurs when actions: i) increase greenhouse gas emissions; ii) disproportionately burden the most vulnerable; iii) have high opportunity costs; iv) reduce incentives to adapt; and v) lead to path dependency (Barnett and O'Neill, 2010). The equity dimension is a particularly critical yet often neglected one, especially as adaptation options can have unforeseen negative spill-over effects (Adger et al., 2005; Adger et al., 2009; Hallegatte, 2009).

Second, adapting to climate change will come at a cost. The challenge here will be to determine who bears these costs and how to share them. This is a significant challenge on two levels: firstly for governments, and secondly for society more generally. From a government perspective, the challenge is to determine how to share the costs between the different levels of government. Local governments are generally seen as having primary responsibility for implementing adaptation policies, yet they already need to balance an increasingly long list of competing needs and priorities and often work on limited budgets and resources (Leitch et al., 2010; Measham et al., 2011). From a society's perspective, this challenge revolves around the issues of fairness and equity, in terms of who benefits from and who pays for adaptation. For example, Australian cities have inherited a legacy of past planning decisions that placed infrastructure and development in areas that are likely to be severely affected by climate change impacts (Department of Climate Change, 2009). As McDonald (2010) points out, individual property owners may have to bear the bulk of costs, however, this might result in prohibitive or unavailable insurance options, thereby calling for governments to provide compensation. Thus, taxpayers would be paying for the inadequate decisions made in the past by property owners, developers and governments without directly benefiting from it (Macintosh, 2010). 
Third, the long-term implications of climate change require a long-term approach to adaptation planning, which does not necessarily fit in well with the current strategic planning framework and short-term political cycles (Wilson, 2006). This mismatch in planning horizons represents a significant challenge for governments in their planning endeavours, particularly at the local level. To minimise the vulnerability of areas at risk of climate change impacts, it is critical to get the timing of planning responses right, whether they are related to the relocation, accommodation and/or defence of structures and communities (Macintosh, 2010). For anticipatory adaptation action governments may need to consider adaptation responses that carry an inherent prohibitive upfront cost that is compounded by the uncertainty related to climate change impacts. Comparatively, delaying planning responses could equally be costly as demonstrated by costs associated with extreme weather events that affected Australia in the last few years (The World Bank and Queensland Reconstruction Authority, 2011).

Finally, achieving the appropriate governance and institutional set up and coordination processes to reflect the multi-scalar and multi-sectoral aspects of planning for climate change adaptation in urban areas is also challenging (Bulkeley, 2010; Daniell et al., 2011; Jäger and Moll, 2011). For example, while land use and development controls in Australia are largely the responsibility of local governments, support from higher order governments, including state and federal levels, is imperative for effective adaptation to occur (Leitch et al., 2010). Additionally, greater horizontal collaboration and coordination will only take place if inter-departmental rivalry, competing interests and attitudes and differences in administrative cultures and goals are overcome (Storbjork, 2010).

\section{Second Set of Challenges: Planning Across Borders - insights from the Gold Coast- Tweed border region}

There are numerous institutional arrangements that inhibit integrated planning responses, including spatial (local - State jurisdictional boundaries), vertical (national - state - local interactions) and sectoral boundaries. As such planning across borders, like climate change adaptation, is complex and challenging. Steele et al. (2012) argue that cross-border institutional arrangements need to take into consideration and address issues related to geographical, institutional and political fragmentation. These issues are context specific and reflect the nature of existing administrative and policy processes as well as community characteristics. Consequently, it is important to improve our understanding of how specific cross-border regions identify and confront challenges to cross-border institutional arrangements. Taking a case study approach (Flyvberg, 2006), we identify these challenges by focusing on messages elicited by stakeholders from the Gold Coast (QLD) and Tweed (NSW) border region. This region was selected as our case study because: (i) it comprises 
two rapidly growing coastal local government areas located across two state borders (see Figure 1); and (ii) it is likely to be vulnerable to future climate change impacts (Hennessy et al., 2007). It thus offers good scope for the discussion of planning challenges involving cross-border regions in the light of a changing climate.

\section{- Please insert Figure 1 here -}

As part of a larger research project, two separate methods were used to collect empirical data in the case study area, including a one day workshop and twenty three semi-structured interviews. Research participants were from the Gold Coast and Tweed local government areas, Queensland and New South Wales State government agencies and non-government organisations (NGOs) active in the region (see Table 1). Twenty five stakeholders attended the workshop which aimed to extract insights from existing cross-borders regulatory mechanisms implemented in the Gold Coast/Tweed region to inform climate change adaptation. In parallel, semi-structured interviews aimed to drill down into the details of existing cross-border arrangements in the case study region to elicit an understanding of the complexities of cross-border arrangements across scales (from national to local).

- Please insert Table 1 here -

Stakeholders identified a range of challenges confronting the case study region, ranging from governance and operational issues through to legislative barriers and institutional values (see Table 2).

\section{- $\quad$ Please insert Table 2 here -}

However, for the specific purpose of this paper which focuses on a cross-border infrastructure project, we will only expand on three of those challenges: (i) misaligned legislative frameworks; (ii) operational issues impeding coordination in planning processes; and (iii) differences in institutional values associated with political priorities and protocols/processes. The rationale behind the selection of these challenges is two-fold: first, they are key challenges commonly confronting a cross border setting and provide great capacity for discussion in the TRESBP case; and second, they are likely to have major implications for planning for climate change adaptation across state borders. It is important to highlight that these challenges are interconnected and have cascading implications for cross-border collaboration. For example, although planning is implemented at the local 
government level it is regulated by state-level policies and thus collaborating local governments are required to abide by their state's policies and processes. As confirmed by all groups of stakeholders, these planning arrangements lead to conflicting operational issues impeding effective coordination between local and state governments in the border region. An example is provided by an interviewee:

'In the past there hasn't been a great deal of emphasis on that [resolving cross-border issues], and I think a classic example of that would be the Bypass, seven kilometres long, five kilometres sits in one State and two kilometres in the other. New South Wales refused to contribute anything to it, whereas it's been a plus to both sides of the border. So you actually had Queensland, when they were building that they had to adapt to the New South Wales environmental laws rather than the Queensland laws ...'

Harmonised or aligned state planning policies between two neighbouring states would therefore facilitate cross-border collaboration between local governments under different state jurisdictions. Stakeholders also stressed that misaligned state government legislation often leads to responses to specific issues purely from a state-centric perspective and to the development of isolated policies and programs. As exemplified by a local government interviewee below:

'It's constantly changing [regulatory frameworks] ... I think if you've got policies that have been changed constantly on both sides of the border. You've got different political requirement per side of the border and if you got different political parties both sides of the border getting everything to line up is extremely difficult.'

In this context, the allocation of funds to large-scale infrastructure projects that could benefit the community from both sides of the border and beyond are likely to be hindered by ongoing changes in regulatory frameworks set by political interests within individual boundaries. Additionally, multi-scale political interests were also clearly identified to play a critical role in determining funding availability and therefore impacting cross-border collaboration involving urban infrastructure projects. As commented by a State government officer:

'The other thing that makes it more difficult is the resources, in order to be able to build a lot of this infrastructure, you'll get arguments between state governments and both local governments about who's going to pay for what .... so you get patchwork which stems primarily from inadequate resources.'

\section{Planning across borders under a changing climate}

In this section, we focus on the TRESBP case to discuss firstly how the challenges of planning across borders were addressed and secondly the implications for planning for climate change adaptation across state borders. 
The nature of the problem addressed by TRESBP was two-fold: the blockage of the Tweed River mouth (NSW) hindering navigation access to the Tweed River; and the extensive erosion of southern Gold Coast beaches (QLD) caused by training walls erected on the Tweed side in the early 1960s to address the blockage of the Tweed River mouth. A joint initiative of the Queensland and New South Wales Governments, TRESBP is a coastal engineering project which serves the interests of multiple stakeholders, including property owners and developers, tourist operators, commercial fisherman, recreational fishermen and surfers. On a day-to-day basis, TRESBP benefits not only the interest groups that initially lobbied for its instalment, such as the marine industry, but also permanent residents and visitors to the area as it provides access to the river as well as maintains the beaches on the Gold Coast side. The project is jointly funded by the NSW and QLD state governments and by Gold Coast City Council with support from Tweed Shire Council. An Advisory Committee provides recommendations to the Ministers and consists of four members of the community, two State government officers appointed by respective state ministers and two local government representatives. To date this project has an overall cost of \$A99.7M (1999/2000 - 2010/2011), with ongoing maintenance costs of between $\$ A 6.7$ - 9.8M spent per annum between 2005/06 - 2010/11. The commitments for the ongoing maintenance and operation of TRESBP have been contracted until September 2024 and are contributed by the NSW government (50\%), QLD government (25\%) and Gold Coast City Council (25\%).

From a purely institutional lens, TRESBP is considered a successful cross-border institutional arrangement because it was able to deliver and meet its aims (Strauss et al., 2009) and because it transcended the cross-border planning challenges. In the TRESBP case, the selected challenges for cross-border arrangements identified earlier, i.e. the misalignment of legislation and associated operational difficulties and differing political priorities leading to funding and resources disputes, were minimised by the significant commitment to the project by both state and local governments. Firstly, in order to enable the sand bypassing project the QLD and NSW governments concluded a separate agreement providing for detailed description of roles and responsibilities, as well as financial contribution of both parties in the planning, development and implementation stages of the project. The Agreement required ratification by the parliaments in each State. Secondly, while the establishment and ongoing costs of the project are considerable and would be prohibitive for many non-urbanised beaches and smaller local governments (Patterson Britton and Partners, 2006), they were met by financial contributions from the NSW and QLD state governments and Gold Coast City Council and in-kind management assistance from the Tweed Shire Council. Thirdly, both local and state governments are committed to TRESBP and local representation is accessed via the Advisory Committee. Interestingly, 
while addressing coastal erosion normally falls under the ambit of local governments, in this case study it has been addressed by both state and local governments possibly because of the significant economic and cultural investment in this highly urbanised coastal zone (Strauss et al., 2009).

However, can TRESBP also be considered successful under the climate change adaptation lens? The paper explores this thesis using the four climate change adaptation challenges and examines the insights that can be gained for planning across borders under a changing climate.

First, as discussed earlier in this paper, an important aspect to be considered in climate change adaptation is the issue of maladaptation (Barnett and O'Neill, 2010). The need for beach nourishment usually is a response to inappropriate development threatened by and exposed to extreme weather events (Strauss et al., 2009). Consequently, it is important to consider whether projects such as TRESBP will indirectly contribute to increased urban development and, perhaps development density, in areas vulnerable to weather extremes. Although TRESBP might ensure beaches will be maintained after extreme weather events, it does not protect the capital invested in public and private structures in those locations. As a result, under climate change and potential increase in frequency and intensity of extreme weather events, the protection of or minimisation of impacts upon public and private structures in those areas may require additional adaptation measures that could be costly given the extent of current and future urban development. Furthermore, TRESBP altered the natural/original coastal morphology and some of the southern beaches are now considered to be too wide therefore compromising recreational activities, such as fishing and surfing (Castelle et al., 2009), which highlights potential negative spill-over effects from TRESBP and raises the issue of who benefits and who loses from the implementation of this project. While TRESBP may have successfully overcome some of the cross-border planning challenges it is yet to adequately consider the challenge of maladaptation. This failure highlights the need to assess the potential for maladaptation from the outset of cross-border projects.

A second consideration extracted from the TRESBP experience that can inform planning for climate change adaptation is related to the actual costs of the project and its operation. The project comprises a unique example in Australia that demonstrates both the viability of cross-border partnerships and the ability to overcome the issues of financing and responsibility-sharing in border regions (Thom and Lazarow, 2006). In addition, TRESBP has secured funding until 2024, which highlights the possibility of securing long-term funding in cross-border arrangements. These are important insights for adaptation, as firstly climate change impacts will not adhere to administrative boundaries and therefore successful 
adaptation may at times require cross-border collaboration, and secondly the ability to secure long-term funding and share costs appropriately across multiple stakeholders is critical for the viability of any adaptation scheme. However, the long-term viability of similar expensive solutions to addressing climate change impacts elsewhere remains uncertain.

In the TRESBP case the financial investment and commitment established by both state governments directly benefit only a specific geographical location across the Gold Coast/Tweed region. While such state government level support overcomes the limited financial ability some local governments might have given the prohibitive costs of expensive coastal management solutions, it posits questions of equity, path dependency and long-term sustainability, in particular for infrastructure projects. Thom and Lazarow (2006) remind us that the viability of future river entrance training works needs to be considered in the light of whether: (i) there will continue to be pressure from wealthier interest groups in demanding governments spend millions to unblock river entrances in the long-term; and (ii) there will be a need for sand bypassing projects in the future to address down drift nourishment of affected beaches (Thom and Lazarow, 2006:120). From an ethical perspective this raises the question whether state-wide tax payers should continue to bear the costs of expensive ad-hoc solutions that only have localised benefits both geographically and socially.

The third challenge for planning for climate change adaptation across borders relates to the necessity for a long-term approach to adaptation planning. Aligning current planning responses, which are based on short term political cycles (Wilson, 2006), to long-term climate change impacts that may require both a long-term strategic approach as well as a project based cross-border arrangement will prove extremely challenging. In the case of TRESBP, all partners bearing the costs have been bound by agreements that are considered to be long-term in terms of planning initiatives, 20-25 years, as opposed to shortterm political cycles of 3-4 years. Given the extent of the costs involved in keeping TRESBP operative, long-term arrangements are imperative as they secure long-term financial commitment from all parties involved and some security for stakeholders. Such long-term financial commitment is likely to be necessary for other climate change adaptation projects applied to coastal areas involving distinct state jurisdictions such as planned retreat and/or defence mechanisms. The future for projects such as TRESBP is interesting to consider as more coastal properties and infrastructure continue to be impacted around Australia.

The fourth adaptation challenge relates to the multi-scalar and multi-sectoral aspects of adaptation planning. The TRESBP case study represents an example of how challenges associated with misaligned legislative frameworks in cross-border arrangements can be overcome through the creation of specific legislation to guide project implementation and operation. The parliaments of both QLD and NSW ratified a specific TRESBP agreement 
which had been concluded by both States and which provided a detailed description of roles and responsibilities, including the financial contribution of all parties. Adapting to climate change impacts in cross-border regions may thus at times require developing new agreements and enacting specific legislation with a clear delineation of stakeholders' roles and responsibilities and cost-sharing arrangements. Such a process would help to avoid overlapping, conflicting, juxtaposed and uncoordinated adaptation responses (NicholsonCole and O'Riordan, 2009).

Nevertheless, the establishment of cross-border institutional arrangements in Australia has been a challenging process, as described by Steele et al. (2012). Some of the challenges highlighted by these authors include the largely non-statutory and ad-hoc character of these arrangements, their subordination to political manipulation and powerful interest groups, and the difficulties associated with securing funds. While the TRESBP case does have a statutory character and has secured funding until 2024, planning for climate change adaptation will be only one of many issues border regions have to address through crossborder institutional arrangements. Hence, competing political priorities and associated policy interests across borders are likely to place ongoing constraints to the establishment of such agreements for climate change adaptation.

\section{Conclusion}

This paper contributes to the Special Issue's theme of planning across borders by focusing on the challenges to cross-border institutional arrangements and implications for climate change adaptation relevant to the planning sector. It highlighted that planning across borders to address climate change adaptation brings an additional complexity which requires a clear definition of roles and responsibilities of involved parties. This includes sharedresponsibility across a wide range of government layers, the community and the private sector as well as shared-costs and risks. Additionally, resources and funding are a key issue for climate change adaptation, and as such cross-border arrangements need to consider who pays for and who funds adaptation. Generally local governments are seen as responsible for climate change adaptation. However, in border regions where some local governments may not have the necessary funds to implement expensive solutions what is the appropriate level of support that should be sought whilst considering social equity: state level, federal level, private sector, community and/or individual level?

One of the biggest challenges for the planning sector will be to prioritise these adaptation responses, as adaptation, particularly in border regions, cannot simply occur through ad-hoc projects alone but requires more coordinated and programmatic approaches that are 
capable of flexibility as the uncertainties of coastal impacts from climate change unfold. However, measuring successful cross-border adaptation implemented through cross-border arrangements will be challenging as its efficacy will only be confirmed once climate change impacts are felt more frequently and intensively. Consequently, planning responses embedded in cross-border arrangements related to climate change adaptation need to take a long-term approach as well as have sufficient flexibility to enable adaptive management to occur as new knowledge and learning emerge. Finally, the collaboration between parties involved in cross-border arrangements to address climate change needs to go beyond the collaboration per se exercise and take into account potential spill over effects leading to maladaptation. The TRESBP case is presented here as the current best practice response to coastal erosion in Australia, which raises some serious concerns as climate change impacts continue to unfold around us.

\section{Acknowledgements}

The authors would like to thank all stakeholders in the Gold Coast/Tweed region for their time and contribution to this work.

This work was carried out with financial support from the Australian Government (Department of Climate Change and Energy Efficiency) and the National Climate Change Adaptation Research Facility. This work originates from the project SD1108 'Every State for themselves? Learning from cross-border regulatory instruments to support and promote climate change adaptation in Australia'. The views expressed herein are not necessarily the views of the Commonwealth or NCCARF, and neither the Commonwealth nor NCCARF accept responsibility for information or advice contained herein.

\section{References}

Adger, W. and Barnett, J., 2009. Commentary - Four reasons for concern about adaptation to climate change, Environment and Planning A, 41, 2800-2805.

Adger, W, Arnell, N. and Tompkins, E., 2005. Successful adaptation to climate change across scales, Global Environmental Change, 15, 77-86.

Adger, W., Dessai, S., Goulden, M., Hulme, M., Lorenzoni, I., Nelson, D. , Naess L., Wolf, J. and Wreford, A., 2009. Are there social limits to adaptation to climate change?, Climatic Change, 93, 335-354

Barnett, J. and O'Neill, S., 2010. Maladaptation, Global Environmental Change, 20, 211-213. 
Berrang-Ford. L., Ford. J. and Paterson, J., 2011. Are we adapting to climate change?, Global Environmental Change, 21, 25-33.

Blanco, H., Alberti, M., Forsyth, A., Krizek, K., Rodriguez, D., Talen, E., and Ellis, C., 2009. Hot, congested, crowded and diverse: Emerging research agendas in planning, Progress in Planning, 71, 153-205.

Bulkeley, H., 2010. Cities and the governing of climate change, The Annual Review of Environment and Resources, 35, 229-253.

Bulkeley, H., Schroeder, H., Janda, K., Zhao, J., Armstrong, A., Chu, S. and Ghosh, S., 2009. Cities and Climate Change: The role of institutions, governance and urban planning. Report prepared for the World Bank Urban Symposium on Climate Change.

Castelle, B., Turner, I., Xavier, B. and Tomlinson, R., 2009. Beach nourishments at Coolangatta Bay over the period 1987-2005: Impacts and lessons, Coastal Engineering, 56, 940-950.

Daniell, K., Manez Costa, M., Ferrand, N., Kingsborough, A., Coad, P. and Ribarova, I., 2011. Aiding multi-level decision-making processes for climate change mitigation and adaptation, Regional Environmental Change, 11, 243-258.

Department Of Climate Change, 2009. Climate Change Risks to Australia's Coast. A first pass national assessment, Commonwealth Government of Australia.

Flyvberg, B., 2006. Five misunderstandings about case-study research, Qualitative Inquiry, $12,219-245$.

Ford, J., Berrang-Ford, L. and Paterson, J., 2011. A systematic review of observed climate change adaptation in developed nations, Climatic Change, 106, 327-336.

Hallegatte, S., 2009. Strategies to Adapt to an Uncertain Climate Change, Global Environmental Change, 19, 240-247.

Hennessy, K., Fitzharris, B., Bates, B., Harvey, N., Howden, M., Hughes, L., Salinger, J. and Warrick, R., 2007. Australia and New Zealand. In : M. Parry, O. Canziani, J. Palutikof, P. Van Der Linden and C. Hanson, eds. Climate Change 2007: Impacts, Adaptation and Vulnerability. Contribution of Working Group II to the Fourth Assessment Report of the Intergovernmental Panel on Climate Change. Cambridge: Cambridge University Press, 507540.

Jäger, J. and Moll, P., 2011. Adaptation to climate change: tools and methods, Regional Environmental Change, 11, 213-215. 
Leitch, A., Harman, B. and Lane, M., 2010. From blueprint to footprint: climate change and the challenge for planning, in: T. Bonyhady, A. Macintosh and J. McDonald, eds., Adaptation to climate change. Law and policy, The Federation Press, Sydney, pp. 63-79.

Macintosh, A. 2010. A theoretical framework for adaptation policy, in: T. Bonyhady, A. Macintosh and J. McDonald, eds., Adaptation to climate change. Law and policy, The Federation Press, Sydney, pp. 38-62.

McDonald, J. 2010. Paying the price of adaptation: compensation for climate change impacts. In: Adaptation to climate change. Law and policy, in: T. Bonyhady, A. Macintosh and J. McDonald, eds., Adaptation to climate change. Law and policy, The Federation Press, Sydney, pp. 234-264.

Measham, T. G., Preston, B. L., Smith, T. F., Brooke, C., Gorddard, R., Withycombe, G. and Morrison, C., 2011. Adapting to climate change through local municipal planning: barriers and challenges, Mitigation and Adaptation Strategies for Global Change, 16, 889-909.

Morrison, T., 2007. Multiscalar Governance and Regional Environmental Management in Australia, Space and Policy, 11, 227-41.

Nicholson-Cole, S. and O'Riordan, T., 2009. Adaptive governance for a changing coastline: science, policy and publics in search of a sustainable future. In: N. Adger, I. Lorenzoni, and K. O'Brien, eds. Adapting to Climate Change: thresholds, Values, Governance, Cambridge University Press, pp. 368-383.

Norman, B., 2009. Planning for coastal climate change. An insight into international and national approaches, Department of Planning and Community Development, Victoria Government, Australia.

Patterson Britton and Partners, 2006. Scoping Study on the Feasibility to Access the Cape Byron Sand Lobe for Sand Extraction for Beach Nourishment. Prepared for the Byron Shire Council. Issue no. 3.

Perkmann, M., 2007. Policy entrepreneurship and multilevel governance: a comparative study of European cross-border regions. Environment and Planning C: Government and Policy, 25, 861-879.

Reilly, J. and Schimmelpfennig, D., 2000. Irreversibility, uncertainty, and learning: portraits of adaptation to long-term climate change, Climatic Change, 45, 253-278.

Repetto, R., 2008. The climate crisis and the adaptation myth. Working Paper No. 13. School of Forestry and Environmental Studies, Yale University, New Haven, CT. pp. 21. 
Serrao-Neumann, S., Low Choy, D., van Staden, R., Crick, F., Sahin, O., Chai, G. and Guan, H., 2011. Climate Change Impacts on Road Infrastructure Systems and Services in South East Queensland: Implications for Infrastructure Planning and Management', in State of Australian Cities Conference 2011 Proceedings, State of Australian Cities National Conference 2011, Melbourne, Australia.

Steele, W., Sporne, I., Shearer, S., Singh-Petersen, L., Serrao-Neumann, S., Crick, F., Dale, P., Low Choy D. and Eslami-Endargoli, L., 2012. Learning from cross-border arrangements to support climate change adaptation in Australia - Stage 1, Urban Research Program Research Monograph 14, Griffith University, Available from: http://www.griffith.edu. au/environment-planning-architecture/urban-research-program/publications/researchmonographs [Accessed 20 June 2012].

Storbjork S., 2010. It takes more to get a ship to change course': barriers for organizational learning and local climate adaptation in Sweden, Journal of Environmental Policy and Planning 12, 235-254.

Strauss, D., Tomlinson, R. and Hunt, S., 2009. Profile response and dispersal of beach nourishment: Gold Coast, Australia, Journal of Coastal Research, 56, 133-137.

The World Bank and Queensland Reconstruction Authority, 2011. Queensland Recovery And Reconstruction In The Aftermath Of The 2010/2011 Flood Events And Cyclone Yasi, Available from: http://www.qldreconstruction.org.au/publications-guides/reports/world-bankreport [Accessed 20 September 2012].

Thom, B. and Lazarow, N., 2006. Environmental history and decision-making, in: Lazarow, N., Souter, R., Fearon, R \& Dovers, S (eds.). Coastal management in Australia: Key institutional and governance issues for coastal natural resource management and planning, CRC for Coastal Zone, Estuary and Waterway Management , 117-124.

Wilson, E., 2006. Adapting to climate change at the local level: the spatial planning response, Local Environment: The International Journal of Justice and Sustainability, 11, 609-625.

Zimmerman, R. and Faris, C., 2010. Infrastructure impacts and adaptation challenges, Annals of the New York Academy of Science, 1196, 63-85. 


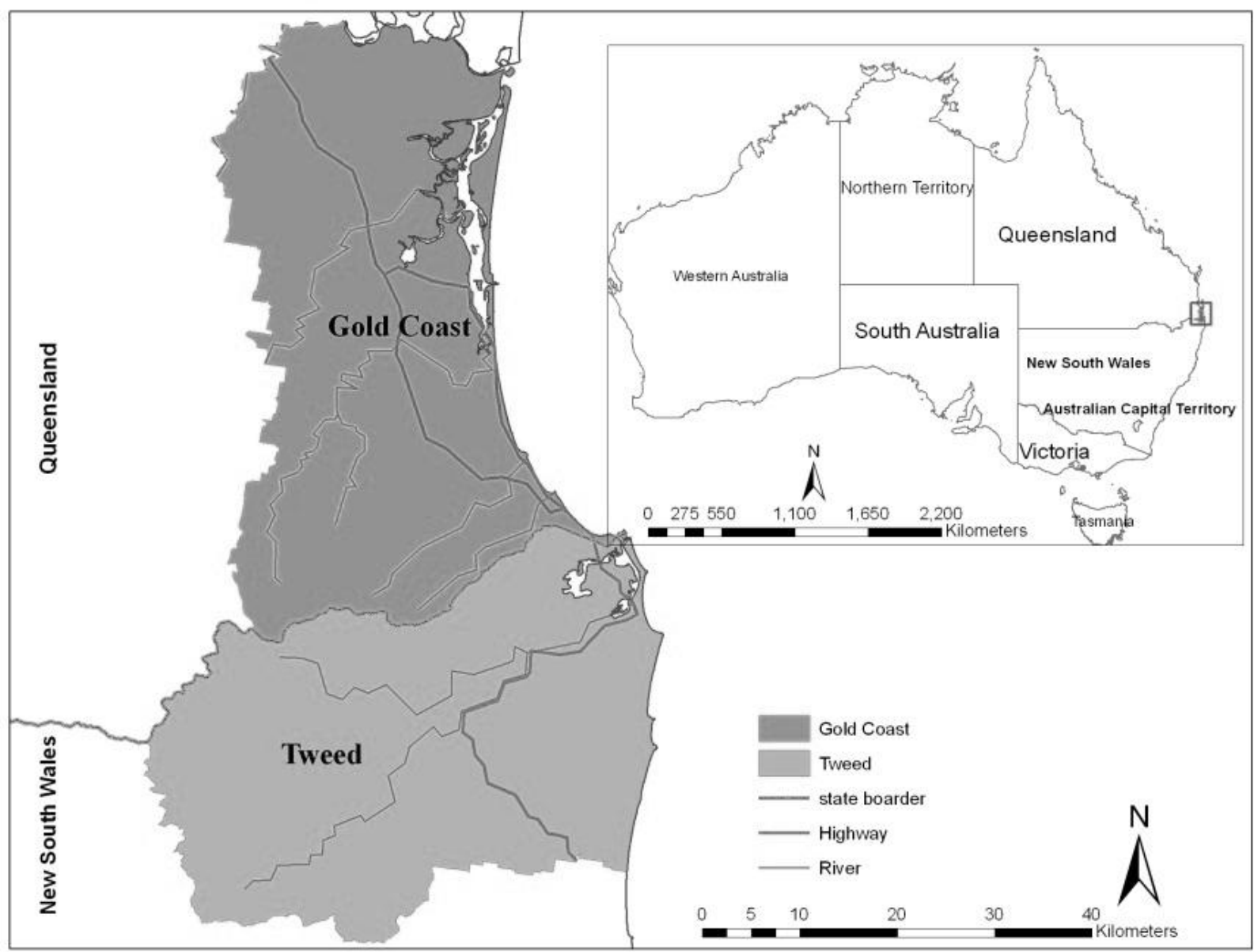

Figure 1: The case study location - Gold Coast/Tweed region 
Table 1: Workshop and Interview participants

\begin{tabular}{|l|l|c|c|}
\hline $\begin{array}{c}\text { Data Collection } \\
\text { Method }\end{array}$ & \multicolumn{1}{|c|}{ Stakeholders } & NSW & QLD \\
\hline \multirow{4}{*}{ Interviews } & Local Government & 6 & 5 \\
\cline { 2 - 4 } & State Government & 5 & 6 \\
\cline { 2 - 4 } & NGOs & 1 & \\
\hline \multirow{3}{*}{ Workshop } & Local Government & 4 & 2 \\
\cline { 2 - 4 } & State Government & 8 & 6 \\
\cline { 2 - 4 } & NGOs & 3 & 2 \\
\hline
\end{tabular}

Table 2: Challenges for cross-border initiatives identified by stakeholders.

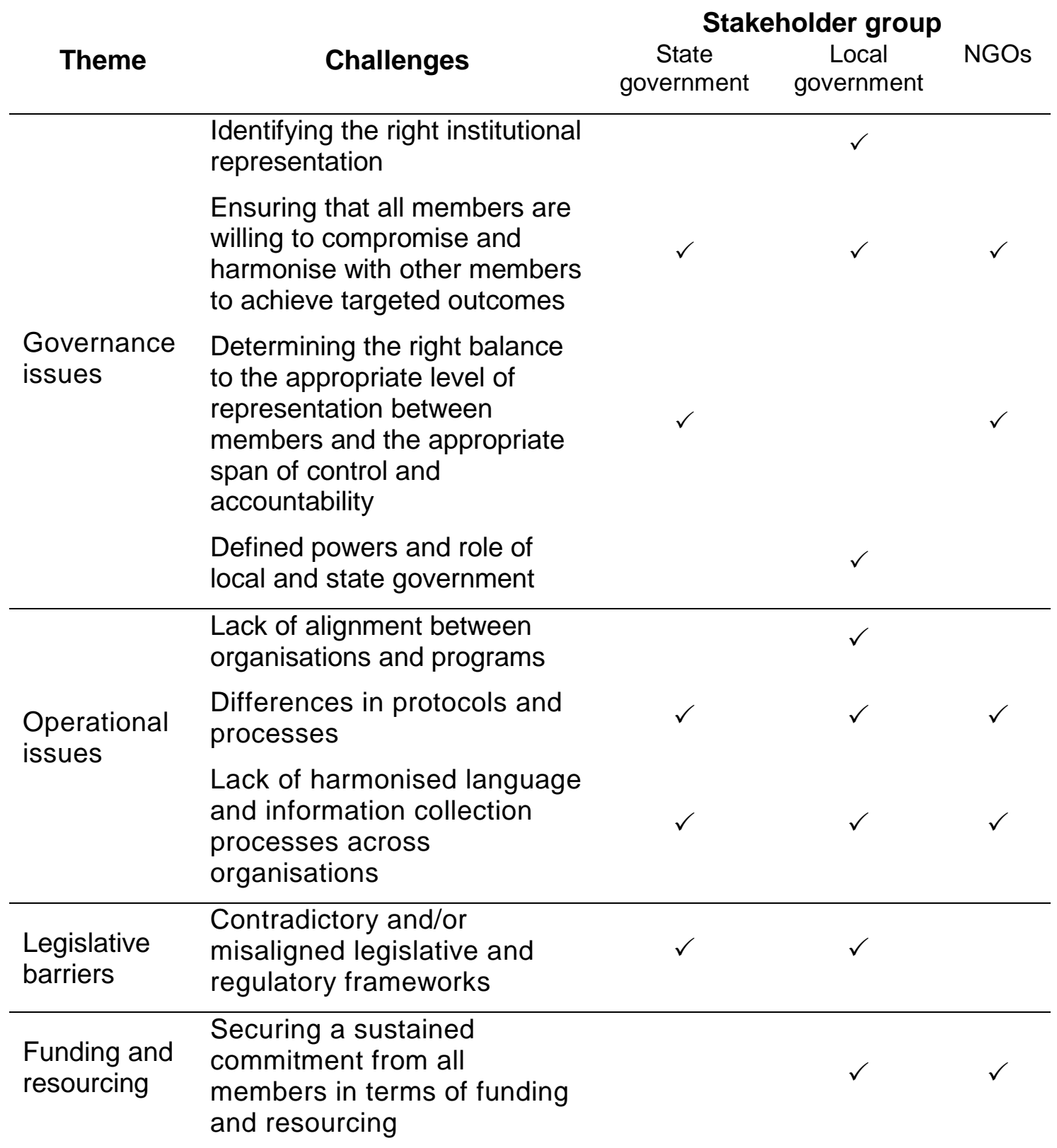


Theme

Challenges

Securing co-funding and resource sharing at local and state government levels for the broader border region

Differences in political priorities

Institutional values

Transcending the cultural divide

Isolated ownership mentality

Leadership Limited political will or support
Stakeholder group

$\begin{array}{lll}\checkmark & \checkmark & \checkmark \\ \checkmark & \checkmark & \\ \checkmark & \checkmark & \\ \checkmark & \checkmark & \checkmark\end{array}$

